\title{
PELATIHAN DASAR-DASAR ALGORITMA DAN PEMOGRAMAN UNTUK MEMBANGKITKAN MINAT SISWA-SISWI SMK PADA DUNIA PEMOGRAMAN
}

\author{
Zaenal Abidin ${ }^{1}$, Permata ${ }^{2}$, Dina Amelia ${ }^{3}$, Rachmi Marsheilla Aguss ${ }^{4}$, Ilham Solehudin ${ }^{5}$ \\ Universitas Teknokrat Indonesia ${ }^{1,2,3,4,5}$
}

Email : zabin@ @eknokrat.ac.id ${ }^{1}$, permata@ teknokrat.ac.id ${ }^{2}$, amelia.dina@ teknokrat.ac.id ${ }^{3}$, rachmi.ma@teknokrat.ac.id ${ }^{3}$, harloom.developer@gmail.com5

\begin{abstract}
Received: (30 Agustus 2021)
Accepted: (5 September 2021)

Abstract

One of the majors in SMK PGRI 1 Limau is the Multimedia department. Special PKM activities in the Multimedia department carried out are Basic Algorithm and Programming Training for students of SMK PGRI 1 Limau. This training aims to open their initial horizons and their interest in the world of programming. The training materials that have been given are (1) Pretest, (2) Session 1: Surgery on the Potential of the World of Work in the field of Computers, (3) Session 2: Algorithm and Basic Programming of Sequences in Python, (4) Session 3: Algorithm and Basic Programming on branching in Python, (5) Session 4: Algorithms and basic programming about looping in Python, and (6) Posttest. The implementation of PKM in the Targeted Schools has been carried out using the lecture method in class and programming exercises in the computer laboratory of SMK PGRI 1 Limau. In general, the visit to SMK PGRI 1 Limau is 4 visits according to the details and schedule of activities that have been made. The results of this training can be seen from the increase in the average score of the pretest students, namely At the beginning of the meeting with the students of SMK PGRI 1 Limau, the participants were given 10 essay questions whose answers were open and closed answering. Eight open answering questions and two closed answering questions. Questions are made according to the level of knowledge of SMK students about basic and simple questions about algorithms and programming. The results of the pretest showed that their initial ability was minimal, namely the average student was able to answer 1.67 questions. Then the posttest results showed that the average score of the students was able to answer 8.33 questions. The improvement of students' ability in completing the posttest increased by $66.67 \%$.
\end{abstract}

Published : (15 September 2021

Keywords: Algorithm, Programming, Python, Training, Postest

\section{Abstrak}

Salah satu jurusan yang ada SMK PGRI 1 Limau yaitu jurusan Multimedia. Kegiatan PKM khusus di jurusan Multimedia dilakukan adalah Pelatihan Dasar-dasar Algoritma dan Pemograman bagi siswa SMK PGRI 1 Limau. Pelatihan ini bertujuan agar membuka cakrawala awal dan ketertarikan mereka akan dunia programming. Materi pelatihan yang telah diberikan adalah (1) Pretest, (2) Sesi 1 : Bedah Potensi Dunia Kerja bidang Komputer, (3) Sesi 2: Algoritma dan Pemograman Dasar Runtunan di Python, (4) Sesi 3 : Algoritma dan Pemograman Dasar tentang pencabangan di Python, (5) Sesi 4 : Algoritma dan Pemograman dasar tentang perulangan di Python, dan (6) Posttest. Pelaksanaan PKM Sekolah Binaan telah dilaksanakan dengan metode ceramah di kelas dan latihan pemogragraman di laboratorium komputer milik SMK PGRI 1 Limau. Secara umum kunjungan ke SMK PGRI 1 Limau 4 kali kunjungan sesuai dengan rincian dan jadwal 



\begin{abstract}
kegiatan yang telah dibuat. Hasi pelatihan ini terlihat dari peningkatan nilai rata-rata siswasiswi pretest yaitu Di awal pertemuan dengan siswa-siswi SMK PGRI 1 Limau, para peserta diberikan 10 soal essay yang jawabannya bersifat open answering dan closed answering. Delapan soal open answering dan dua closed answering. Pertanyaan dibuat sesuai dengan tingkat pengetahuan siswa-siswa SMK akan soal-soal mendasar dan sederhana tentang algoritma dan pemograman. Hasil pretest menunjukannya minimnya kemampuan awal mereka yaitu rata-rata siswa-siswi mampu menjawab 1.67 pertanyaan. Kemudian hasil posttest menunjukan nilai rata-rata siswa-siswi mampu menjawab 8.33 pertanyaan. Perningkatan kemampuan siswa dalam menyelesaikan posttest meningkat sebesar $66.67 \%$.
\end{abstract}

Kata Kunci: Algoritma, Pemograman, Python, Pelatihan, Postest

To cite this article:

Zaenal Abidin, Permata, Dina Amelia, Rachmi Marsheilla Aguss, Ilham Solehudin. (2021). PELATIHAN DASAR-DASAR ALGORITMA DAN PEMOGRAMAN UNTUK MEMBANGKITKAN MINAT SISWA-SISWI SMK PADA DUNIA PEMOGRAMAN. Journal of Technology and Social for Community Service (JTSCS), Vol(2), 54-62.

\title{
PENDAHULUAN
}

SMK PGRI 1 Limau adalah sebuah sekolah menengah kejuruan swasta yang berdiri di lahan yang tepat didepannya terhampar pemandangan bukit nan indah, udara yang sejuk serta bernuansa pegunungan yang asri. Jurusan yang ada di SMK PGRI 1 Limau adalah jurusan Perhotelan dan Multimedia dengan 6 rombongan belajar. Lokasi SMK PGRI 1 Limau tepatnya ada di sisi jalan raya pekon Antarbrak kecamatan Limau kabupaten Tanggamus.

Awal mula berdirinya SMK PGRI 1 Limau adalah dipelopori oleh 10 pemuda di kecamatan Limau yang menginginkan agar para generasi penerus mereka yang ada di kecamatan Limau tidak mengalami putus sekolah. Kondisi geografis yang berbukit dan pegunungan membuat jarak untuk para siswa menempuh sekolah tingkat menengah atas terasa jauh baik ke arah bawah pegunungan atau bahkan ke atas pegunungan yang bisa menembus ke SMAN 1 Limau. Pada awal mulanya berdiri pada tahun akademik 2017/2018 SMK PGRI 1 Limau dalam proses belajar mengajarnya menumpang di SDN 1 Antarbrak kemudian karena harus masuk jam pagi maka pindah ke Madrasarah Ibtidaiyah Antarbrak. Pada tahun akademik 2019/2020 SMK PGRI 1 Limau meluluskan angkatan pertamanya dari dua jurusan yaitu Perhotelan dan Multimedia. Tepat dalam waktu satu tahun terakhir ini SMK PGRI 1 Limau telah memiliki lahan sekolah sendiri yang dibangun atas swadaya masyarakat Pekon Antarbrak dan mendapatkan bantuan dana dari pemerintah dalam bentuk bantuan operasionalsekolah (BOS).

Seiring dengan perkembangan zaman dan waktu yang terus berkembang terjadi perubahan pada kebutuhan pendidikan dan guru di SMK PGRI 1 Limau. Hal ini turut serta 'memaksa' SMK PGRI 1 Limau untuk beradaptasi dan terus berbenah diri baik dari sisi pembangunan infrastruktur sekolah maupun kemampuan atau kinerja tenaga pendidik yang ada di SMK PGRI 1 Limau untuk bisa mengikuti perkembangan sistem pendidikan SMK minimal di tingkat kabupaten Tanggamus dengan baik. Sistem pendidikan adalah strategi atau metode yang digunakan dalam proses belajar mengajar untuk mencapai tujuan agar peserta didik dapat secara aktif mengembangkan potensi yang ada di dalam dirinya(Puspaningtyas \& Dewi, 2020).

Saat ini aktifitas belajar mengajar dilakukan secara online karena kondisi covid-19. Kami memilihsekolah untuk program PKM sekolah binaan di SMK PGRI 1 Limau didasari oleh kondisi sekolah yang masih berumur relatif muda yaitu 4 tahun berjalan dan rasa keterbukaan / pihak SMK PGRI 1 Limau sangat terbuka untuk menerima masukan-masukan dari luar sekolah yang berpotensi untuk meningkatkan potensi dan kualitas kinerja tenaga pendidik(Setiawansyah et al., 2021), sehingga pada akhirnya akan memberi dampak positif pada siswasiswa SMK PGRI 1 Limau. SMK PGRI 1 Limau juga memiliki jurusan yang berlatarbelakang bidang IT yaitu jurusan Multimedia. Pendidikan adalah salah satu faktor terpenting dalam usaha pembangunan yang dilakukan oleh sebuah Negara. Menurut (Salahudin, 2011) pendidikan merupakan upaya pengembangan potensi manusiawi dari para peserta didik, baik berupa fisik, cipta maupun karsa agar potensi tersebut menjadi nyata dan dapat berfungsi bagi perjalan kehidupan. Potensi mengeksplorasi kendala atau masalah berdasarkan Manajemen Berbasis Sekolah (MBS) masih terbuka lebar(Megawaty, 2020). 


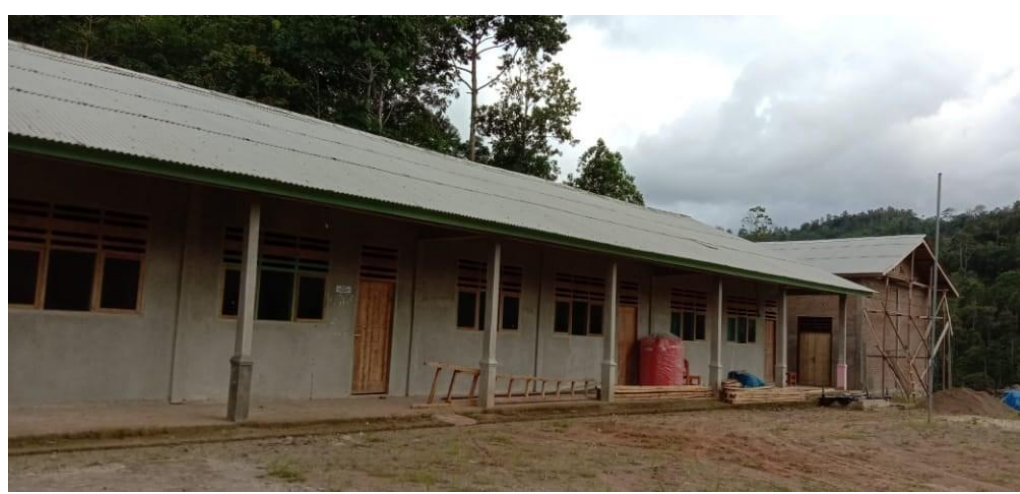

Gambar 1. Kondisi Saat Kunjungan Pertama ke SMK PGRI 1 Limau

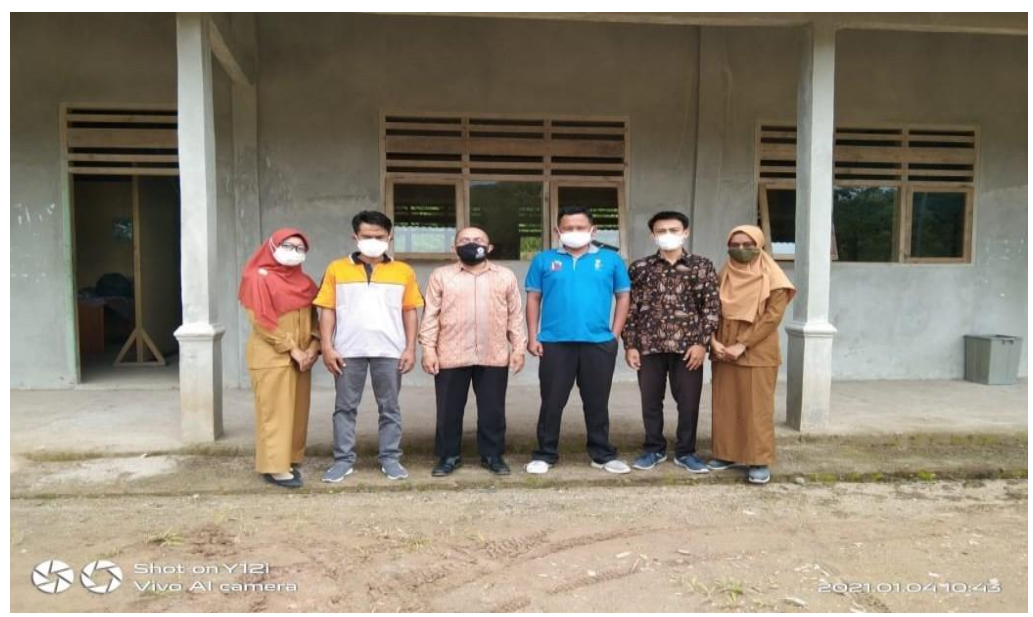

Gambar 2. Kunjungan Pertama ke SMK PGRI 1 Limau

Berdasarkan hasil wawancara dengan wakil kepala sekolah bidang kurikulum dan perwakilan para guru di SMK PGRI 1 Limau, terdapat empat permasalahan yang diutarakan kepada ketua tim PKM saat kunjungan ke sekolah pada 4 Januari 2021 yang lalu. Akan tetapi khusus pada laporan PKM ini adalah khusus pada permasalahan pada jurusan Multimedia. Adapun permasalahan yang dihadapi adalah permasalahan keempat ditemui dari sisi sangat minimnya pemahaman siswa-siswa akan pengetahuan dasar-dasar algoritma bahkan sangat minim kemampuan pemograman tingkat dasar. Pada saat kondisi pandemi COVID-19 ini para siswa belajar hanya menggunakan alat bantu berupa SMS dan Mesengger atau Whatsapp / Telegram. Pertemuan siswa dan guru untuk membahas materi pemograman tingkat dasar hampir tidak ada. Hal tersebut menjadi sesuatu yang sangat riskan dan menyedihkan melihat sebagai jurusan berbasis IT yaitu jurusan Multimedia seharusnya siswa-siswi SMK mendapatkan bekal dasar dasar pemograman yang harusnya mencukupi karena itu adalah hal mendasar bagi siswasiswa SMK berbasis IT. Tepat di lokasi sekolah yang berada di atas perbukitan kondisi sinyal internet hampir 100 $\%$ tidak terjangkau / terakses.

Berdasarkan permasalahan yang telah dikemukakan diatas maka pada Program Pengabdian kepada Masyarakat (PkM) kami bersama mitra yaitu SMK PGRI 1 Limau akan mencoba menyelesaikan permasalahan tersebut dengan memberikan / melaksanakan pelatihan dengan beragam materi yaitu (1) diawali dengan Pretest guna mengetahui kemampuan awal siswa-siswi, (2) Sesi 1 : Bedah Potensi Dunia Kerja bidang Komputer, (3) Sesi 2 : Algoritma dan Pemograman Dasar tentang runtunan / Sequence in Python, (4) Sesi 3 : Algoritma dan Pemograman Dasar tentang pencabangan / Branching in Python, (5) Sesi 4 : Algoritma dan Pemograman dasar tentang perulangan / Looping in Python, dan (6) diakhiri dengan Posttest guna mengukur efek dari peningkatan pemahaman siswa-siswi akan dunia pemograman (Lamhot, 2017; Nagar, 2017).

Adapun permasalahan yang dihadapi adalah permasalahan di SMK PGRI 1 Limau adalah karena ditemui fakta sangat minimnya pemahaman siswa-siswa akan pengetahuan bahkan kemampuan pemograman tingkat dasar. Solusi akan minimnya pemahaman siswa-siswa akan pengetahuan bahkan kemampuan pemograman tingkat dasar adalah sebagai berikut: Pelatihan di kelas dan di Laboratorium Komputer milik SMK PGRI 1 Limau. Ada lima pokok bahasan yang menjadi bahasan untuk mencoba menjadi solusi pada 
masalah ini. Termasuk di dalamnya pembahasan pertama mengenai wawasan potensi dunia kerja pasca pendidikan SMK dan potensi kuliah di bidang komputer. Kemudian materi dasar terkait dasar-dasar algoritma dan pemograman. Diantaranya meliputi pendahuluan algoritma dan pemograman, runtunan, pencabangan, perulangan dan praktek di laboratorium komputer di SMK PGRI 1 Limau.

Pelatihan dibagi menjadi 2 sesi. Sesi pertama direncanakan, yaitu tanggal 18 Maret 2021 fokus pada wawasan dunia kerja pasca pendidikan SMK dan pendahuluan algoritma dan pemograman. Sesi lanjutan pertama direncanakan, yatu tanggal 19 Maret 2021 fokus pada runtunan, pencabangan dan perulangan. Siswa diberikan penjelasan secara detail terkait potensi kerja setelah pendidikan di SMK jurusan multimedia kemudian dilanjutkan potensi untuk melanjutkan kuliah di Universitas Teknokrat Indoneisa di bidang komputer bagi siswa SMK jurusan multimedia. Lalu kegiatan sesi lanjutan pertama dilanjutkan dengan pembahasan secara detail dasar-dasar algoritma dan pemograman meliputi pendahuluan algoritma dan pemograman, runtunan, pencabangan dan perulangan.

Sementara sesi kedua diisi dengan materi praktek langsung di kelas dan di lab SMK PGRI 1 Limau. Sesi kedua direncanakan pada 22 April 2021 fokus pada mencoba secara langsung pemograman diantaranya meliputi pendahuluan algoritma dan pemograman, runtunan, pencabangan dan perulangan. Sesi lanjutan kedua direncanakan, yatu tanggal 27 April 2021 fokus praktek langsung di lab SMK PGRI 1 Limau ada runtunan, pencabangan dan perulangan.

\section{METODE PELAKSANAAN \\ Tempat dan Waktu}

Pelaksanaan pelatihan dasar-dasar algoritma dan pemograman dilakukan di kelas dan di laboratorium komputer SMK PGRI 1 Limau terletak di Jalan Pekon Antar Brak Kecamatan Limau Kabupaten Tanggamus Provinsi Lampung. Kegiatan ini dimulai dari dilaksanakan pada 18 - 19 Maret 2021, 22 April dan 27 April 2021.

\section{Khalayak Sasaran}

Sasaran dalam kegiatan pelatihan ini adalah siswa-siswi kelas 10 dan kelas 12. Kelas 11 tidak mengikuti dikarekan sedang ada pelaksanaan PKL dari sekolah ke tempat PKL yang telah ditunjuk. Tidak semua siswa- siswa kelas 10 dan kelas 12 bisa mengikutinya dikarekan faktor utama sedang dalam keadaan pandemi covid-19 dan beberapa siswa-siswi juga bekerja membantu orang tuanya di kebun. Sebuah kondisi yang tidak dapat dipaksakan.

\section{Teknik Pengumpulan Data}

Teknik pengumpulan data yang dilakukan pada pelaksanaan PKM ini adalah dengan menggunakan uji pretest sebelum pelatihan dasar-dasar algoritma dan pemograman dengan mekanisme 2 soal closed answering dan 8 soal open answering dan setelah pelatihan dasar-dasar algoritma dan pemograman menggunakan uji posttest guna melihat efek dari pelatihan terhadap siswa-siswa SMK PGRI 1 Limau.

\section{Metode Pengabdian}

Tahapan pelaksanaan dalam kegiatan Pelatihan Dasar-dasar Algoritma dan Pemograman Untuk Membangkitkan Minat Siswa-siswi SMK Pada Dunia Pemograman meliputi hal-hal berikut ini :

a. Penggalian informasi ke ketua Jurusan Multimedia terkait bagaimana kondisi siswa-siswi SMK Jurusan Multimedia. Hasilnya diperoleh bahwa karena kondisi COVID-19 ini berdampak sangat signifikan pada proses belajar mengajar di SMK. Hal lain yang tidak kalah pentingnya adalah KETIADAAN SINYAL INTERNET tepat pada posisi di sekolah karena sekolah berada pada posisi diatas bukit dan secara geografis sekolah dikepung oleh bukit pada semua penjuru arah sehingga tidak ada sinyal dan hal ini sangat mengganggu proses belajar mengajar. Teknologi yang digunakan dalam belajar juga masih sangat minim yaitu hanya via Whatsapp atau Telegram dan SMS.

b. Hal pertama yang dilakukan oleh tim PKM adalah menggali informasi via pretest untuk menggali info kemampuan awal siswa. Hasil pretest kami gunakan untuk analisa awal kemampuan siswa-siswi SMK PGRI 1 Limau,

c. Lalu pemberian motivasi kepada siswa-siswi SMK PGRI 1 Limau berupa pencerahan dan Bedah Potensi Dunia Kerja bidang Komputer, 
d. Kemudian Sesi Pemberian materi dan Pelatihan baik di kelas dan di Laboratorium Komputer milik SMK PGRI 1 dengan materi: Algoritma dan Pemograman Dasar tentang Sequence in Python, Algoritma dan Pemograman Dasar tentang Branching in Python, Algoritma dan Pemograman dasar tentang Looping in Python

e. Hal terakhir yang dilakukan oleh tim PKM adalah menggali informasi via posttest untuk menggali info kemampuan / pengetahuan akhir siswa pasca diberikan materi dan Pelatihan baik di kelas dan di Laboratorium Komputer milik SMK PGRI 1 . Hasil pretest dan posttest kami gunakan untuk analisa kemampuan siswa-siswi SMK PGRI 1 Limau baik sebelum dan sesudah materi dan Pelatihan baik di kelas dan di Laboratorium Komputer milik SMK PGRI 1.

Rincian kegiatan kunjungan dilaksanakan pada bulan Maret dan April 2021. Sesi pertama dilaksanakan tanggal 18 Maret 2021 dengan fokus pada (1) pretest, (2) Pemberian motivasi dan wawasan dunia kerja pasca pendidikan SMK dan pendahuluan algoritma dan pemograman. Sesi lanjutan pertama dilaksanakan pada tanggal 19 Maret 2021 fokus pada runtunan, pencabangan dan perulangan. Siswa diberikan penjelasan secara detail terkait potensi kerja setelah pendidikan di SMK jurusan multimedia kemudian dilanjutkan potensi untuk melanjutkan kuliah di Universitas Teknokrat Indoneisa di bidang komputer bagi siswa SMK jurusan multimedia.Lalu kegiatan sesi lanjutan pertama dilanjutkan dengan pembahasan secara detail dasar-dasar algoritma dan pemograman meliputi pendahuluan algoritma dan pemograman, runtunan, pencabangan dan perulangan. Sampel foto-foto kegiatan pada tanggal 18 Maret dan 19 Maret 2021 diberikan di bagian lampiran pada laporan ini.

Sementara sesi kedua diisi dengan materi praktek langsung di kelas dan di lab SMK PGRI 1 Limau. Sesi kedua dilaksanakan pada 22 April 2021 fokus pada mencoba secara langsung pemograman python di laboratorium komputer milik SMK PGRI 1 Limau adapun materi prakteknya diantaranya meliputi pendahuluan algoritma dan pemograman, runtunan, pencabangan dan perulangan. Sesi lanjutan kedua dilaksanakan, yatu tanggal 27 April 2021 fokus pada mencoba secara langsung pemograman python di laboratorium komputer milik SMK PGRI 1 Limau praktek langsung di lab SMK PGRI 1 Limau ada runtunan, pencabangan dan perulangan. Tindak lanjut pelatihan tersebut adalah pembuatan grup Whatsapp antara dosen pemateri dengan siswa-siswi SMK PGRI 1 Limau guna menunjang jika mereka ingin konsultasi secara online. Link grup WA nya adalah https://chat.whatsapp.com/EPNXLrARoja7OGFBRIAW2qq

Partisipasi dan Kontribusi Mitra Terhadap Pelaksanaan adalah dibuktikan dengan support penuh dari kepala sekolah SMK PGRI 1 Limau yang memberikan keleluasaan waktu, kelas dan laboratorium komputer SMK PGRI 1 Limau digunakan dalam kegiatan ini di semua jadwal yang telah kami laksanakan. Ketua jurusan Multimedia juga mendukung penuh seperti halnya kepala sekolah. Antusiasme siswa-siswi SMK PGRI 1 Limauu juga sangat terasa ketika diberikan materi dan pelatihan terkait dasar-dasar algoritma dan pemograman. Foto-foto yang ada pada bagian lampiran bisa menggambarkan semangat siswa-siswi dalam kegiatan PK ini.

\section{HASIL DAN PEMBAHASAN}

Dari hasil pengabdian kepada masyarakat yang dilakukan oleh Tim PkM Universitas Teknokrat Indonesia ada 2 hasil luaran yang telah dicapai pada pelatihan ini, yaitu:

Luaran IPTEKS pertama berupa pengetahuan baru bagi siswa dalam materi Pelatihan dasar-dasar algoritma dan pemograman. Kegiatan tersebut disusun dalam bentuk pelatihan dasar-dasar algoritma dan pemograman bagi siswa kelas 10 dan 12 jurusan multimedia. Luaran IPTEKS kedua berupa skill dasar pada pemograman Python yang sifatnya mendasar bagi siswa dalam materi Pelatihan dasar-dasar algoritma dan pemograman. Kegiatan tersebut disusun dalam bentuk uji coba contoh coding pemograman Python sesuai materi pada pelatihan dasar-dasar algoritma dan pemograman bagi siswa kelas 10 dan 12 jurusan multimedia.

Ada lima pokok topik yang menjadi bahasan, termasuk di dalamnya pembahasan pertama mengenai wawasan potensi dunia kerja pascapendidikan SMK dan potensi kuliah di bidang komputer, kemudian materi dasar terkait dasar-dasar algoritma dan pemograman yang meliputi (1) pendahuluan algoritma dan pemograman, (2) runtunan, (3) pencabangan, (4) perulangan dan praktek di laboratorium komputer di SMK PGRI 1 Limau, (5) wawasan potensi dunia kerja bidang IT untuk siswa-siswi SMK Multimedia.

Pelatihan dibagi menjadi 2 sesi. Sesi pertama, yaitu tanggal 18 Maret 2021 fokus pada wawasan dunia kerja pascapendidikan SMK dan pendahuluan algoritma dan pemograman. Sesi lanjutan pertama, yatu tanggal 19 Maret 2021 fokus pada runtunan, pencabangan dan perulangan. Siswa diberikan penjelasan secara detail terkait potensi kerja setelah pendidikan di SMK jurusan multimedia kemudian dilanjutkan potensi untuk melanjutkan kuliah di Universitas Teknokrat Indoneisa di bidang komputer bagi siswa SMK jurusan multimedia. Lalu 
kegiatan sesi lanjutan pertama dilanjutkan dengan pembahasan secara detail dasar-dasar algoritma dan pemrograman meliputi (1) pendahuluan algoritma dan pemograman, (2) runtunan, (3) pencabangan, (4) perulangan. Sementara sesi kedua, diisi dengan materi praktek langsung di kelas dan di lab SMK PGRI 1 Limau. Sesi kedua yaitu tanggal 22 April 2021 fokus pada mencoba secara langsung pemrograman meliputi (1) pendahuluan algoritma dan pemograman, (2) runtunan, (3) pencabangan, (4) perulangan. Sesi lanjutan kedua, yatu tanggal 27 April 2021 fokus praktek langsung di lab SMK PGRI 1 Limau ada runtunan, pencabangan dan perulangan. Dosen pemandu PKM Zaenal Abidin dan Permata mengatakan, tujuan dari kegiatan pelatihan ini adalah untuk memberikan tambahan pengetahuan serta membangkitkan motivasi terhadap para siswa SMK PGRI 1 Limau agar menjadi lebih percaya diri dan tertarik pada dunia pemograman ketika kelak mereka akan lulus dari jurusan multimedia.

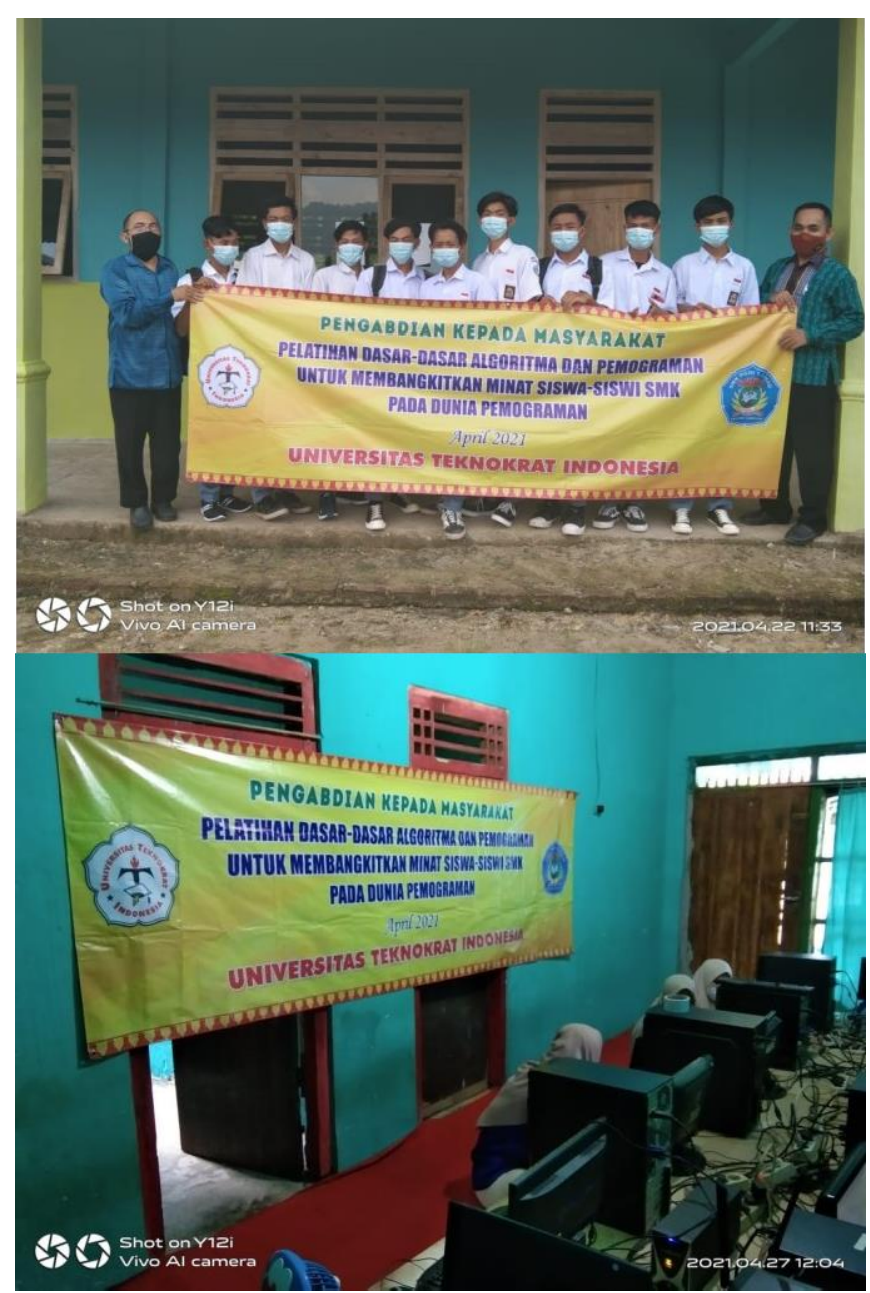

Gambar 5. Sampel Foto Kegiatan Pelatihan Dasar-dasar Algoritma dan Pemograman di SMK PGRI 1 Limau

Dokumentasi foto-foto kegiatan dan video pelatihan dasar-dasar algoritma dan permograman disediakan secara lengkap di tiga link dibawah ini.

https://drive.google.com/drive/folders/1QsfMUo-3Xw6rTYQ0_AQTptHZ-CfS55Eb?usp=sharing https://drive.google.com/drive/folders/1U2UTZoXousnr4b2J7EDerPd25hkGwSLs?usp=sharing https://drive.google.com/drive/folders/1jRypOJ82WC1bRbanxxn9ChqfFeehnHON?usp=sharing Publikasi Kegiatan Pelatihan Dasar-dasar Algoritma dan Pemograman di SMK PGRI 1 Limau telah terbit di link yang dapat diakses di: 
https://radarlampung.co.id/universitas-teknokrat-indonesia-berikan-pelatihan-dasar-algoritma-dan-pemogramandi-smk-pgri-1-lima

Peningkatan pemberdayaan mitra pada pelaksanaan PKM di SMK PGRI 1 Limau dapat dilihat berdasarkan pelaksanaan hasil pretest dan posttest pada Pelatihan Dasar-dasar Algoritma dan Pemograman di SMK PGRI 1 Limau. Di awal pertemuan dengan siswa-siswi SMK PGRI 1 Limau, para peserta diberikan 10 soal essay yang jawabannya bersifat open answering dan closed answering. Delapan soal open answering dan dua closed answering. Pertanyaan dibuat sesuai dengan tingkat pengetahuan siswa-siswa SMK akan soal-soal mendasar dan sederhana tentang algoritma dan pemograman. Hasil pretest dan posttest dapat dilihat pada tabel 1 dibawah ini.

Tabel 1. Hasil pretest dan posttest

\begin{tabular}{|l|c|c|}
\hline $\begin{array}{l}\text { NAMA SISWA-SISWI SMK PGRI 1 } \\
\text { LIMAU }\end{array}$ & PRETEST & POSTTEST \\
\hline Darmawan & 2 & 7 \\
\hline M. YUNARDI & 2 & 7 \\
\hline HERWAN & 2 & 7 \\
\hline DIKI SUBAKTI & 2 & 9 \\
\hline SELY YUNITA & 2 & 9 \\
\hline LIVANNY SULISTYA P & 2 & 7 \\
\hline IFAN AL-WANIZAR & 2 & 10 \\
\hline TITIN PARDILAH & 2 & 9 \\
\hline KIRANA SOEKMA FITRIA HARYADI & 3 & 9 \\
\hline AULIA SALSABILA & 2 & 10 \\
\hline YULIANA SARI & 2 & 9 \\
\hline DWI PUTRI NURHASANAH & 0 & 9 \\
\hline VITRA NOFITA & 0 & 6 \\
\hline DWI ANTIKA PUTRI & 0 & $\mathbf{8 . 3 3 3 3 3 3 3 3 3}$ \\
\hline RIZKY SAPUTRA & $\mathbf{1 . 6 6 6 6 6 6 6 6 7}$ & $\mathbf{6 6 . 6 6 6 6 6 6 6 7}$ \\
\hline Nilai Rata-rata & & \\
\hline Kenaikan dari pretest ke posttest (\%) & 2 & \\
\hline
\end{tabular}

Hasil pretest menunjukan pengetahuan awal bagi tim pelaksana PKM untuk dapat menilai judgement awal akan knowlegde terkait algoritma dan pemograman yang dimiliki oleh siswa-siswa SMK PGRI 1 Limau.

Hasil pretest menunjukannya minimnya kemampuan awal mereka, hal ini tercermin dari kemampuan menjawab 10 soal hanya rata-rata siswa-siswi mampu menjawab 1.67 pertanyaan. Setelah selesai pretest para siswa diberikan materi Bedah Potensi Dunia Kerja bidang Komputer, Algoritma dan Pemograman Dasar tentang Runtunan / Sequence di Python, Algoritma dan Pemograman Dasar tentang pencabangan / Branching di Python, Algoritma dan Pemograman dasar tentang perulangan / Looping di Python, dan terakhir dilakukan Posttest. Sesuai yang tertera pada tabel 1 , hasil posttest menunjukan peningkatan secara siginifikan. Perningkatan kemampuan siswa dalam menyelesaikan posttest meningkat sebesar $66.67 \%$.

\section{KESIMPULAN}

Berdasarkan pemaparan di atas, kesimpulan pada pelaksanaan PKM khusus untuk siswa-siswa Multimedia berjalan dengan lancar, baik dan terukur. Lancarnya pelaksanaan didukung sepenuhnya oleh Universitas Teknokrat Indonesia dalam pendanaan yang maksimal dan pelaksanaan didukung sepenuhnya oleh pihak sekolah SMK PGRI 1 Limau baik atas ketersediaan semua sarana dan prasarana yang diberikan selama pelatihan ini.

Pelatihan ini terlaksana dengan baik karena pelatihan ini bertujuan agar membuka cakrawala awal dan ketertarikan mereka akan dunia programming. Materi pelatihan yang telah diberikan adalah (1) Pretest, (2) Sesi 
1 : Bedah Potensi Dunia Kerja bidang Komputer, (3) Sesi 2 : Algoritma dan Pemograman Dasar tentang Runtunan / Sequence di Python, (4) Sesi 3 : Algoritma dan Pemograman Dasar tentang pencabangan / Branchingdi Python, (5) Sesi 4 : Algoritma dan Pemograman dasar tentang perulangan / Looping di Python, dan (6) Posttest.

Pelatihan ini terukur melalui pelaksanaan pretest dan posttest pasca pelatihan. Dari hasil nilai pretest dan posttest diperoleh angka peningkatan signifikan dalam hal kemampuan menjawab 10 soal sederhana yang terkait dasar-dasar algoritma dan pemograman bagi siswa-siswa SMK PGRI 1 Limau sebesar $66.67 \%$.

\section{UCAPAN TERIMA KASIH}

Ucapan terimakasih kami sampaikan kepada Universitas Teknokrat Indonesia yang telah memberikan hibah Pengabdian Kepada Masyarakat (PKM) tahun pelaksanaan 2021. Kami ucapkan terima kasih juga kepada Kepala Sekolah SMK PGRI 1 Limau Kabupaten Tanggamus yang telah memberikan kesempatan kepada kami untuk melaksanakan kegiatan pengabdian masyarakat.

\section{REFERENSI/DAFTAR PUSTAKA}

Lamhot, S. (2017). Algoritma dan Pemrograman. Yogyakarta. Andi Offset.

Megawaty, D. A. (2020). SISTEM MONITORING KEGIATAN AKADEMIK SISWA MENGGUNAKAN WEBSITE. Jurnal Tekno Kompak, 14(2), 98-101.

Nagar, S. (2017). Introduction to Python for Engineers and Scientists: Open Source Solutions for Numerical Computation. Apress.

Puspaningtyas, N. D., \& Dewi, P. S. (2020). Persepsi Peserta Didik terhadap Pembelajaran Berbasis Daring. JPMI (Jurnal Pembelajaran Matematika Inovatif), 3(6), 703-712.

Salahudin, A. (2011). Filsafat Pendidikan, Bandung: CV. Pustaka Setia.

Setiawansyah, S., Adrian, Q. J., \& Devija, R. N. (2021). Penerapan Sistem Informasi Administrasi Perpustakaan Menggunakan Model Desain User Experience. Jurnal Manajemen Informatika (JAMIKA), 11(1), 24-36. 


\section{BIOGRAFI PENULIS}

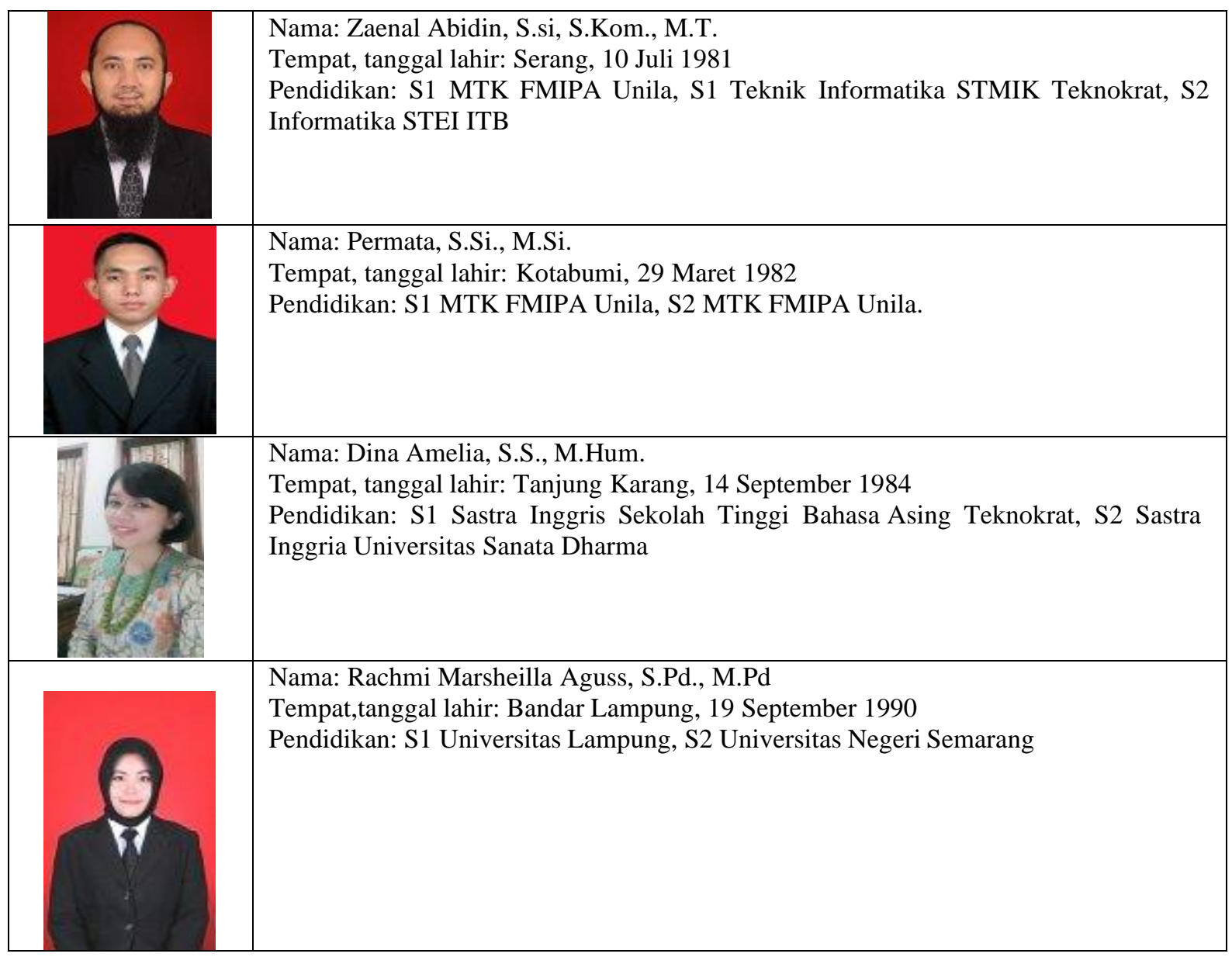

